\title{
TOPONÍMIA E LITERATURA: O NOME DO RIO COMO REFERÊNCIA NO CONTO GENTE DA GLEBA
}

\begin{abstract}
Lidiane Silva Araújo Guimarães Mestranda em Estudos da Linguagem pela Universidade Federal de Goiás - Regional Catalão (UFG/RC) lidianearauj02005@hotmail.com

Kênia Mara de Freitas Siqueira Doutora em Letras e Linguística pela Universidade Federal de Goiás (UFG) Professora da Universidade Estadual de Goiás (UEG) e do Programa de Mestrado em Estudos da Linguagem (PPGEL/RC/UFG) e do Programa de Pós-Graduação em Língua, Literatura e Interculturalidade (POSLLI/UEG)
\end{abstract}

\section{RESUMO}

Subjacente ao topônimo estão as motivações, que são as percepções do denominador acerca do lugar nomeado, bem como há indícios dos marcos históricos e das características físicas e sociais do lugar nomeado. Assim, os estudos toponímicos têm como objetivo investigar os nomes próprios de lugar buscando deslindar tais motivações. 0 foco é o conjunto de hidrônimos que são mencionados no conto "Gente da Gleba", texto publicado no livro "Tropas e Boiadas", de Hugo de Carvalho Ramos. Os hidrônimos são como pontos no mapa pelo qual os personagens se locomovem e se orientam face ao desenrolar da narrativa. Espera-se contribuir para os estudos toponímicos, principalmente no que refere à relação entre tais estudos e a literatura goiana a fim de demonstrar como os nomes de lugares se entrelaçam aos costumes, anseios dos personagens.

Palavras-chave: toponímia, literatura, ecolinguística, hidrônimos.

\begin{abstract}
Underlying the toponym are motivations, composed of the perception of the name giver about the place named, as well as indications of its historical marks and physical and social characteristics. Therefore, toponymic studies investigate names of places in an attempt to understand such motivations. The focus of this study is a group of hydronyms mentioned in Hugo de Carvalho Ramos' short story "Gente da Gleba", published in "Tropas e Boiadas". Hydronyms are like checkpoints on the map in which characters move and locate themselves throughout the course of the story. We expect to contribute to toponymic studies, mainly in reference to the relationship between such studies and the literature from Goiás state, and to demonstrate how names of places intertwine with the hopes and habits of the characters.
\end{abstract}

Keywords: toponymy, literature, ecolinguistics, hydronyms. 


\section{Introdução}

O léxico de uma língua permite conhecer entre outros fatores, elementos da cultura e da história de um povo, além de informações sobre a topografia, pois o léxico comporta os nomes das coisas e esses podem, quando motivados, trazer informações e referências diversas de tais elementos. Por meio dos signos linguísticos, a sociedade ao mesmo tempo em que acessa, dissemina os aspectos da cultura em seu caráter mutável e heterogêneo, uma vez que pode "Estabelecer contatos com objetos, fatos ou realidades imateriais, categorizá-los, classificá-los são ações possíveis graças à capacidade mental e, sobretudo, cultural de representação através de signos" (PAULA, 2015, p. 134). O uso e a escolha dos signos linguísticos revelam características que diferenciam culturalmente um povo do outro.

Os estudos toponímicos, dado seu caráter interdisciplinar, ou seja, estudos em consonância com outras disciplinas, como a história e a geografia, demonstram como fatores de diversas ordens afloram no momento da escolha do nome para determinado lugar. Assim, um signo toponímico se diferencia de outros signos linguísticos pelo seu caráter motivado em contraponto com a arbitrariedade que, de acordo com Saussure (1996), caracteriza os demais signos linguísticos. Pode-se dizer que a escolha do nome, do lugar depende de um motivo, que tem sua origem relacionada a fatores diversos.

Os estudos toponímicos podem subsidiar pesquisas em diferentes âmbitos de abordagem. Couto e Couto (2016, p. 389) ao exporem o caráter multimetodológico da linguística ecossistêmica, reiteram a necessidade de se focar os fenômenos linguísticos holisticamente. Para esses autores, "teorias parcelares" fatiam os dados linguísticos 
desvinculando-os da rede da qual fazem parte como fios muito bem engendrados nas diversas situações de interação.

Posto isso, para esse estudo pretende-se considerar os aspectos históricos e culturais que permeiam os topônimos mencionados no conto "Gente da Gleba", de Hugo de Carvalho Ramos. Nesse sentido, acolhem-se entre outros aportes teóricos, as propostas de Dick (1990), Siqueira (2015), (2016), (2017) e Couto (2007) e (2017) para a escolha e descrição dos topônimos referentes aos nomes de rios identificados principalmente, no conto mencionado.

\section{Toponímia}

A atividade de nomeação atende a inúmeras necessidades humanas envolvidas nos atos de interação: identificação, referenciação, indicação e posse. É por meio dos signos linguísticos que identificar, fazer referência e indicar algo se tornam ações realizáveis. Seabra salienta que "Em todas as partes do mundo, o homem faz uso de signos linguísticos que se fundamentam em seu entorno vivencial, estimulados pela necessidade de nomear, diferenciar e indicar" (2006, p. 139).

A toponímia pode ser definida como área da linguística responsável por investigar os nomes de lugares. Faz parte da onomástica que, por sua vez, ocupa-se dos estudos referentes aos nomes próprios em geral, o que inclui os nomes de pessoas, abordados pela antroponímia. As motivações que determinam a escolha dos nomes de lugares estão relacionadas às percepções do denominador. Percepções que advêm de aspectos culturais, históricos, físicos e geográficos formatados a partir da relação do denominador com o lugar nomeado. Dick sobre os topônimos explica que: 
O valor pragmático do topônimo não se subsume apenas na intencionalidade momentânea ou casual do denominador; é superior a ela, com implicações exteriorizadas, gerando uma tensão dialética entre objetivos, finalidades, escolhas e resultados práticos (2006, p. 100).

Por isso, pode-se dizer que os estudos toponímicos possibilitam acessar marcos históricos, particularidades de determinada região, fatores sociais relevantes, características físicas predominantes do lugar, mesmo que esses aspectos tenham mudado com o tempo. O topônimo pode ser tomado para análise a partir de diferentes perspectivas linguísticas. No que se refere à Ecolinguística, cabe destacar a investigação a partir da relação do denominador com o território nomeado.

Para Couto "o território $(T)$ é o componente mais concreto de comunidade, é o seu suporte material" (2007, p. 102). Em outras palavras, os aspectos físicos, históricos e culturais que possam estar impressos no topônimo são fatores dependentes do modo como a comunidade se constitui em determinado território. De acordo com a abordagem ecossistêmica dos fatos linguísticos, há de se considerar sempre as inter-relações entre língua (L), população (P) e território (T) quando se pretende ver os fenômenos da linguagem de forma holística.

Dependendo da abordagem, o território pode ser conceituado como espaço ou lugar. O lugar geográfico, T nomeado, apenas "existe" ou passa a existir a partir da nomeação, ou melhor, a partir do momento que recebe um nome, o topônimo. Ser batizado, receber um nome faz parte da configuração dos espaços de existência, eles passam a existir pelo nome que os designa. Pelo nome criam-se pontos de referência, criam-se mapas de orientação dos espaços, esses mapas, conforme Couto (2017) constituem o mapa mental do falante. É preciso, pois, nomear os lugares para falar deles, 
para servir de referências, para construir mapas de localização. Segundo Siqueira e David T é físico em primeira instância, entretanto faz emergir traços sensoriais muitas vezes não "audíveis" nos recônditos da memória de L.

$T$ [...] pode-se estender por espaços não físicos, porém sensoriais, culturais no sentido de que existem no ambiente mental da língua, ou melhor, no ecossistema mental da língua que guarda as informações acerca de como a língua foi formada, armazenada e processada no cérebro, nas conexões neurais. Nesse sentido, pode-se sempre refletir sobre a questão da adaptação, seja em que âmbito ela se der: adaptação ao território, à cosmovisão do grupo. Embora em muitas situações, sejam espaços criados no imaginário popular, as fronteiras e limites do território físico geográfico são mentalmente traçadas, as fronteiras do lugar nomeado se encontram bem definidas pelos indivíduos que o habitam (2014, p. 122).

Pelo nome, os lugares além de serem percebidos, são vivenciados, tornam-se audíveis aos sentimentos do nomeador. Ao serem percebidos, os lugares comportam conteúdos ligados às diferentes sensações, às intenções e imaginação do falante. Numa obra de cunho regionalista como a de Ramos (1998), os topônimos assumem funções essenciais no texto, ligadas à imaginação, haja vista que os fatos recriados por Ramos devem ser situados geograficamente, porque ressaltam a importância do lugar para que as ações dos personagens se deem da maneira como são narradas nos contos. Os personagens transitam, interagem com o lugar, saltam da memória.

Um rio é um elemento referencial importante, pois traça divisas, estabelece domínios, alarga ou estreita T. O rio segue sinuoso seu curso pelas vastidões do território. Dito de outra forma, nome $(\mathrm{N})$ e lugar ( $\mathrm{L}$, território para a proposta ecossistêmica) formam uma díade, cujas dimensões literárias podem trazer à cena tradições locais, modos de vida particulares, aspectos históricos e ambientais, 
singularidades de $\mathrm{P}$ que abrangem quase sempre vínculos afetivos de pertencimento àquele espaço simbolizado pelo nome, que o referencia, e habitável por essa referência nuclear da existência humana.

Pode-se pensar que o nome e o território formam um único elemento, uma vez que T é conhecido e identificado por seu topônimo. Em relação às comunidades de língua, convém acrescentar que, muitas vezes, $\mathrm{L}$ recebe o mesmo nome (ou o gentílico desse nome) de $T(T+N)$. Assim, em se tratando de estudos toponímicos, o esquema do Ecossistema Integral da Língua, assume T na díade T (lugar nomeado) + o topônimo que o designa.

Figura 1 - Ecossistema Integral da Língua

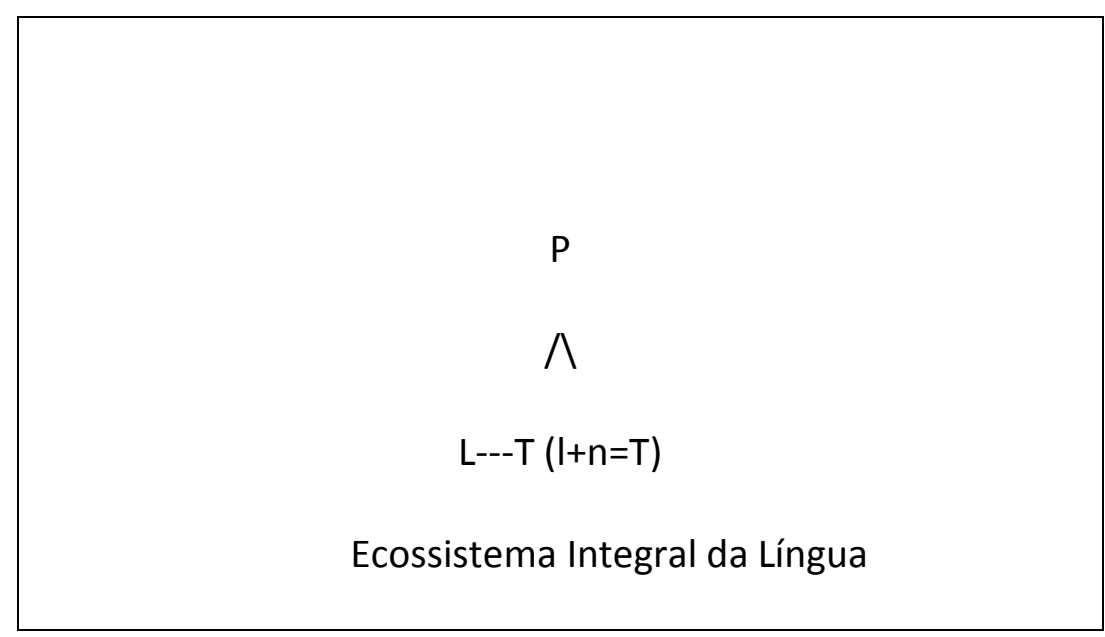

Fonte: Adaptada de Couto (2016)

Em que o Ecossistema Integral da Língua é constituído de $P$, de $L$ e de $T$ (díade $L+N$ ) mais o nome do lugar, já que T se constitui como unidade política, entre outras tantas questões, mediante a nomeação.

\section{Toponímia e literatura}


O estudo da toponímia traz possibilidades diferentes em relação às fontes de dados, ou seja, o acesso aos topônimos, bem como informações da sua origem estão disponíveis, tanto em documentos históricos, quanto em cartografias. Uma fonte de dados a ser considerada nos estudos toponímicos refere-se à literatura, que pela necessidade de definir um espaço para a narrativa, descreve um espaço real ou cria um espaço fictício. Desta forma, é possível afirmar que "as disciplinas onomásticas oferecem subsídios para análises literárias" (CARVALHINHOS, 2009, p. 85), de modo que as duas áreas podem se servir simultaneamente. $\mathrm{O}$ fato de um determinado topônimo apresentar-se numa obra literária demonstra como a descrição do espaço é dependente do nome designado a ele. Para Carvalhinhos:

Quando o topônimo figura em uma obra ficcional pode-se afirmar que a escolha desse nome passou por um crivo duplo, pois o autor cria um topônimo (ou escolhe dentro de um paradigma já existente) com o objeto deliberado de construir um determinado espaço na sua narrativa $(2009$, p. 88$)$.

Por isso é possível dizer que no caso da relação toponímia e literatura, no que se refere aos topônimos de espaços reais emprestados à obra literária, o topônimo que já fora em determinado momento escolhido pela comunidade para denominar, volta a ser escolhido pelo autor para especificar o espaço da narrativa. Para Carvalhinhos:

se o nome do lugar sofre uma primeira filtragem no ato da denominação [...] podemos afirmar que, no caso da literatura, essa filtragem é dupla e, ainda, que existe (na maioria das vezes) uma intencionalidade na denominação, seja na criação de um espaço, seja na reprodução de um espaço considerado real (2009, p. 83). 
Nesse sentido, o topônimo assume além da função identificadora, a responsabilidade de situar o leitor no espaço da narrativa. Isto é, o nome do lugar, é o ponto de conexão entre o leitor e o espaço da obra. De modo que "o topônimo não é o lugar em si, mas uma de suas representações" (CARVALHINHOS, 2009, p. 83). Essa representação é necessária para criar o espaço da narrativa.

O foco pelo qual o objeto é apreendido enfatiza a relação entre literatura e ambiente, procurando deslindar a maneira pela qual a primeira reconstitui o ecossistema conforme as inter-relações estabelecidas entre o topônimo e o lugar presente na narrativa. Ao marcar os lugares existentes, a narrativa mostra esses elementos como dado histórico e geográfico do ponto de vista da língua e cultura de então e passa a representá-los sob a ótica do indivíduo goiano do início do século XX. Dessa maneira, a literatura pode ser considerada um elemento de civilização, porque se constitui por meio do entrelaçamento de diversos fatores sociais, culturais e, claro, por fatores do ambiente. Devido a sua plurivocidade, uma obra literária, faz parte de um universo simbólico inerente aos seres que compõem um ecossistema.

\subsection{A obra Tropas e Boiadas}

Embora não faça parte desse estudo realizar uma análise literária, é necessário situar a obra que serve de subsídio para a investigação toponímica. O livro de Hugo de Carvalho Ramos, reúne contos com forte apelo a elementos dos lugares goianos. "Tropas e Boiadas", fez com que o autor fosse reconhecido nacionalmente e que as características regionais se tornassem elementos importantes da narrativa. Regiões do cerrado goiano foram traduzidas em prosa sob o olhar arguto do contador das histórias da gente goiana. 
A obra foi publicada há cem anos e pode ser considerada um registro das particularidades do léxico sertanejo goiano da época. Segundo Gomes, “O escritor goiano que vivia no Rio de Janeiro há alguns anos e de lá desvenda Goiás e terras circunvizinhas ao leitor, desperta imediato interesse e movimentação crítica em torno de sua obra" (2009, p. 21). Os textos de Hugo de Carvalho Ramos, mais que descrever as terras goianas, as colocam em lugar de prestígio e evidência.

Ao retratar Goiás em sua obra, Ramos deixa evidente a relevância de discutir traços culturais que diferenciam as regiões. Para Gomes, "Hugo era homem de letras, consciente do seu papel como tal, sabedor das necessidades culturais de seu tempo e com formação intelectual que lhe dava lastro pra figurar entre os melhores escritores nacionais" (2009, p. 15).

Posto isso, é possível afirmar que a obra de Ramos representa o fato de a literatura ser fonte de dados considerável no âmbito da pesquisa científica, pois preserva e divulga traços léxicos e culturais de um povo, de uma região e ainda de determinado tempo da história. Mostra em todos os tons goianos da época, a língua, o lugar, e principalmente, o homem goiano com suas crendices, aspirações, sua visão de mundo banhada quase sempre pelas águas do Araguaia, Tocantins, Paranaíba, Veríssimo, entre outros.

\section{Os hidrônimos}

Os contos reunidos em Ramos (1998) apresentam referência aos lugares onde se desenrolam as ações dos personagens, com léxico toponímico em diferentes níveis. Para esse estudo foram selecionados alguns hidrônimos, porque a água é um dos elementos naturais mais procurados, muitos lugarejos à época do ouro em Goiás, floresceram à 
beira de um riacho, de um pequeno córrego, de um lago ou de um grande rio. A narrativa se situa, mostra-se pelos topônimos, "viajava escoteiro pelas estradas ermas e alagadiças do Caiapó Velho" (RAMOS, 1998, p. 6). Inclusive, o sertão assume alma e é um personagem em quase todos os contos de "Tropas e Boiadas".

A obra faz referência a alguns dos principais elementos hídricos de Goiás, que por meio de seus nomes, retomam aspectos históricos e culturais dos primeiros denominadores dos lugares goianos. São referências a lugares que situam e caracterizam a narrativa. Os excertos abaixo são representativos de como os personagens se situam e se locomovem no chão goiano e como esses lugares constituem parte da história, porque são os lugares das ações narrativas e não outros.

Apanhara umas febres no Veríssimo e vinha por toda viagem tiritando no fundo do carretão. (RAMOS, 1998, p. 15)

- Andava nesse tempo numa comissão de linha telegráfica, porta-mira de turma. Féria boa é verdade, mas trabalho era ali! Isso, rumo do Araguaia, abrindo picada na mata virgem, esse mundão de mato grosso que principia em Jaraguá, beiradeia os rios Uru e das Almas, cai no Araguaia, ganha o Tocantins e vai acabar lá para as bandas do Pará. (RAMOS, 1998 p. 23).

Nesse tempo, talvez no Paranaíba, talvez do outro lado de Minas, em Mato Grosso quem sabe, Benedito viajava longes terras, nas pegadas do negro fugitivo (RAMOS, 1998, p. 51).

Atravessara o Meia-Ponte em Pouso Alto. Seguindo as informações que The dera um rancheiro perto de Morrinhos, enveredou pelo sertão das Abóboras, coito famigerado de relapsos e trânsfugas, onde tem ido às vezes a política estadual suprirse de acostados e facínoras para os motins locais (RAMOS, 1998, p. 55). 
A maioria dos topônimos descritos aparecem no conto "Gente da Gleba", pois nele aparecem mais topônimos e esses são pontos de referência para o desenrolar da narrativa, já que marcam a passagem dos personagens pelo território goiano.

\section{(i) Hidrônimo Almas:}

O Rio das Almas banha o estado de Goiás, sua nascente está localizada no município de Pirenópolis, no limite do Parque Estadual da Serra dos Pireneus. Compõe a bacia do Tocantins. Seu curso corta as cidades de Pirenópolis, Jaraguá e Nova Glória. Seus afluentes são: rio Areias, rio do Peixe, rio Padre Souza e rio Uru. Foi um rio relevante na época da exploração do ouro em Goiás.

Em Cunha, o termo aparece como "essência imaterial do ser humano, espírito. XIII. Do latim anima [...]" (1982, p. 32). Para Machado "é um topônimo frequente em Portugal”. Segundo o autor, o topônimo tem ligação com

uma lenda relativa a luzes brancas e vermelhas que, saindo dos túmulos, em que se enterraram índios mortos em combate numa das margens do rio, voavam para outra margem, onde estavam os índios que escaparam com vida, a fim de que não ficassem sepultados em terreno inimigo (2003, p. 103).

O rio das Almas aparece em inúmeras outras histórias de Goiás, não narradas em "Tropas e Boiadas". A escolha do hidrônimo ilustra a relação do homem com o território e a percepção de si como parte dele, de forma que a escolha do nome do rio decorre daquilo que a comunidade ou o indivíduo observa ou cria em determinado lugar. 


\section{(ii) Hidrônimo Araguaia:}

O rio Araguaiaii tem sua nascente em Goiás na Serra do Caiapó, em Mineiros. Fica próxima ao Parque Nacional das Emas. Pertence à bacia amazônica e ao longo de mais de 2000 km de curso marca as seguintes divisas estaduais: Mato Grosso e Goiás, Mato Grosso e Tocantins e Pará e Tocantins.

Mouzart (2015) apresenta esse termo com origem tupi, significa papagaios mansos, segundo ele, como hidrônimo é provável que signifique rio das araras mansas. Em Tibiriçá "grande afluente da margem esquerda do Tocantins; de Araguaia, de periquito (tupi: aráuáia, rabo de arara)". (2009, p. 22). Além de ser representante da base lexical tupi no português brasileiro, esse hidrônimo exemplifica mais uma vez como o homem tende a observar aspectos físicos relevantes do meio ambiente e depois retratá- lo por meio do nome.

(iii) Hidrônimo Meia Ponte:

O rio Meia Ponte iii é um importante afluente do rio Paranaíba. Sua nascente está no município de Itauçu. A bacia hidrográfica do Meia Ponte localiza-se na região centro-sul do estado de Goiás, essa é uma região consideravelmente populosa, envolve os municípios de Goiânia, Aparecida de Goiânia, Anápolis, Senador Canedo e Itumbiara.

Esse hidrônimo aparece no conto "Gente da Gleba" (também em Madre do Ouro). Andrade (2006) considera duas possibilidades para a motivação desse hidrônimo. A primeira seria devido a uma grande pedra que avançava por cima do rio, formando meia ponte, de modo que os moradores tiveram que construir apenas a outra metade. A outra 
definição afirma que inicialmente, foi armada sobre o rio uma ponte feita com duas peças de madeira, tendo uma delas sido arrastada pelas águas, sobrando apenas meia ponte. Em ambas as teorias de origem do hidrônimo, é evidente que houve observação em relação aos aspectos físicos ou fatos históricos relevantes relacionados ao território.

(iv) Hidrônimo Paranaíba:

O rio Paranaíba ${ }^{\mathrm{iv}}$ nasce num município mineiro homônimo ao rio. A localização do rio, por ser estratégica, foi fundamental para a integração com Goiás. A expedição de Bartolomeu Bueno da Silva passou por esse rio. Seu curso percorre $1160 \mathrm{~km}$ até o Rio Grande, sua foz, corta 193 municípios em Goiás, Minas Gerais e Mato Groso do Sul, além do Distrito Federal.

Esse hidrônimo também aparece no conto "Gente da Gleba". Segundo Mouzart (2015) e Tibiriçá (2009), esse topônimo significa rio ruim ou impraticável. Sampaio (1928, p. 144) atesta esses significados: para o verbete "pará, o mesmo que mbará, ou mará, s. o mar; c. y-pá-rá, aguas (sic) todas colhe, isto é, o colecionador das aguas, Bap. C. No tp. C. pará, é o rio volumoso, o caudal". Tem-se o mesmo para o verbete Paranã e para “Paranahyba (sic), c. paranã-ahyba, grande rio impraticável, ou inavegável; Goyaz (sic), Minas Geraes (sic)”. A característica física do rio, águas abundantes e correnteza forte provavelmente foram determinantes na escolha do hidrônimo, o que evidencia, mais uma vez, a tendência humana de basear o nome do lugar em aspectos físicos do território.

\section{(v) HidrônimoTocantins}


O rio Tocantins ${ }^{\vee}$ nasce no estado de Goiás, entre os municípios de Ouro Verde de Goiás e Petrolina de Goiás. A extensão do rio tem aproximadamente 2.400 km, é o segundo maior curso d'àgua inteiramente brasileiro, percorre quatro estados brasileiros: Goiás, Tocantins, Pará e Maranhão.

O nome deste rio aparece no conto "Gente da Gleba". Segundo Dias (2016) o nome faz referência ao grupo indígena que habitava junto à foz do rio. Cavalcante e Andrade (2009) acrescentam que em sua formação morfológica, o nome Tocantins significa na língua Tupi, nariz de tucano. Em Andrade têm-se: "forma absoluta de oca, a casa, o refúgio, o esconderijo, o abrigo. 112. V. Oca. Alt. roca, Soca. -corr. Ti, ponta, nariz, saliência, proa. Pode ser uma forma contrata de tinga, branco, alvo. V. Ti" (2006, p. 165).

Para Tibiriçá Tocantins de "tucanti, nome de uma var. de tucano com penas brancas no peito, daí seu nome tucan-ti (tucan-tinga), tucano branco; seg. alguns tupinólogos, esse vocábulo quer dizer "nariz de tucano", apelido dado a uma tribo indígena que habitava a região e dera seu nome ao rio" (2009, p. 113). No caso desse hidrônimo é evidenciada por meio do nome a relação entre povo e território, de modo que, em algum momento, foram homônimos.

\section{(vi) Hidrônimo Uru}

O rio Uru ${ }^{\text {vi }}$ guarda muitas histórias, e de cujas margens nasceram algumas cidades goianas. O rio Uru banha os municípios goianos de Mossâmedes, Cidade de Goiás, Itaberaí, Heitoraí, Itapuranga, Uruana e Carmo do Rio Verde. Faz parte da bacia do Tocantins. 
Tibiriçá traz no verbete "uru": "topônimo de duplo sentido: a) uru, certa ave da fam. Dos fasianídeos; b) uru, qualquer tipo de receptáculo, pote, vasilha, cesto etc". Já em Machado (2003, p. 1448), encontra-se apenas: "Do smursu, nome de ave (de origem tupi?)" (2009, p. 117). E ainda em Sampaio (1928): sm. do Tupi u'ru, nome comum às aves galiformes da família dos fasianídeos; também, ave voraz, uma das modalidades do nome urubu. Pode-se deduzir que o hidrônimo seja uma referência à presença dos pássaros no curso do rio, o que evidenciaria um aspecto físico marcante do território como fator determinante na escolha do nome.

\section{Considerações finais}

A discussão acerca do caráter não arbitrário do signo toponímico, principalmente devido a sua natureza referencial, vem direcionando muitos estudos toponímicos no sentido de elucidar fatores que subjazem à escolha dos locativos. Nesse sentido, o conto "Gente da Gleba" possibilita verificar que o topônimo se destaca na linearidade da narrativa, faz emergir o referente trazendo-o para o primeiro plano da memória poética, situando o rio num mapa mental de então. Faz isso por meio do vínculo que existe entre o nome e o lugar. Entre nome e território.

A descrição feita procurou rever a visão de Hugo de Carvalho Ramos acerca do território de Goiás de então, o sertão, os fundões do estado. As designações toponímicas permitem verificar que os lugares são vistos pelos moradores (em relação aos hidrônimos), de diferentes formas, mas sempre se espera que os topônimos incorporem as feições do lugar, sejam como um ponto no mapa que os permite locomoverem e se 
orientarem, pois funcionam (quando referenciados) como descrições definidas, pelas relações de semelhança ou contiguidade entre topônimo e lugar.

Esse estudo permitiu desvendar a relação entre estudos toponímicos e obras literárias, de modo que os topônimos, mais especificamente os hidrônimos, registrados no conto podem ser entendidos como representações culturais das comunidades que os escolheram. Mais que isso, o estudo permitiu, por meio de uma abordagem ecossistêmica, desvendar, pelo menos em parte, a relação entre língua e território. Essa relação é evidenciada no fato dos hidrônimos portarem aspectos físicos relevantes que foram em algum momento observados pelo denominador de modo a se tornarem a motivação do nome escolhido.

Cabe acrescentar ainda que, tanto no que diz respeito à relação entre estudos toponímicos e o corpus literário, quanto aos estudos linguísticos abordados pela visão ecossistêmica há uma amplitude de possibilidades, de modo que não houve a pretensão de esgotar essas abordagens. No entanto, esse estudo permitiu trazer à baila dos estudos onomásticos uma visão no mínimo inovadora dos fatos linguísticos ao considerar a relação da língua e do meio ambiente.

\section{Referências}

ANDRADE, Karylleila dos Santos. Atlas toponímico de origem indígena do estado do Tocantins - Projeto ATITO. Tese (Doutorado em Linguística) - Universidade de São Paulo, 2006. Disponível em:

<www.teses.usp.br/teses/disponiveis/.../TESE_KARYLLEILA_SANTOS_ANDRADE.pdf>. Acesso em: 10 nov. 2017. 
CARVALHINHOS, Patrícia de Jesus. Interface Onomásica/Literatura: A toponímia, o espaço e o resgate de memória na obra Memórias da Rua do Ouvidor, de Joaquim Manuel de Macedo. Cadernos do CNLF (CiFEFil), Rio de Janeiro, VXII, n.10, p. 83 -99, 2009. Disponível em: https:<//www.filoloia.org.br/xiicnlf/10/completo_10.pdf>. Acesso em: 10 nov. 2017. CAVALCANTE, Lynara Raquel; ANDRADE, Karylleila dos Santos. Análise e descrição dos topônimos tocantinenses no contexto da Belém-Brasília. USP, São Paulo, 2009. Disponível em: <dlrv.fflch.usp.br/sites/dlrv.fflch.usp.br/files/12-4.pdf>. Acesso em: 07 nov. 2017.

COUTO, Elza KiokoNakayamaNenoki do; COUTO, Hildo Honório do. Ecolinguística, linguística ecossistêmica e análise do discurso ecológica (ADE). Signótica, Goiânia, v. 28, n. 02, p. 381-404, jul/dez, 2016.

COUTO, Hildo Honório. Comunidade de fala revisistada. Ecolinguística: Revista Brasileira de Ecologia e Linguagem, v. 02, n. 02, p. 49-72, 2016.

COUTO, Hildo Honório. Ecolinguística. Estudo das relações entre língua e meio ambiente. Brasília: Thesaurus, 2007.

COUTO, Hildo Honório. Mapa Mental. Ecolinguística: Revista Brasileira de Ecologia e Linguagem, v. 03, n. 01, p. 206 -227, 2017. Disponível em:

<http://periodicos.unb.br/index.php/erbel/article/view/24561/17630. Acesso em: 08 nov. 2017.

CUNHA, Antônio Geraldo. Dicionário etimológico. 2 ed. Rio de Janeiro: Nova Fronteira, 1982.

DIAS, Ana Lourdes Cardoso. Toponímia dos primeiros municípios tocantinenses. 2016. 208

f. Tese (Doutorado em Letras e Linguística) - Universidade Federal de Goiás, Goiânia, 2016. Disponível em: <https://repositorio.bc.ufg.br/tede/handle/tede/5852>. Acesso em: 11 nov. 2017.

DICK, Maria Vicentina de Paula do Amaral. Fundamentos Teóricos da Toponímia. Estudo de caso: o Projeto ATEMIG - Atlas Toponímico do estado de Minas Gerais (variante regional do Atlas Toponímico do Brasil). In: SEABRA, M. C. T. C. (Org.). O léxico em estudo. Belo Horizonte: Faculdade de Letras/UFMG, 2006. p. 91-117. 
GOMES, Luciana Coelho. Literatura e identidades: o regionalismo de Hugo de Carvalho Ramos. Dissertação. (Mestrado em Teoria Literária). Universidade Federal de Uberlândia, Uberlândia, 2009. UFU. Disponível em:

<https://repositorio.ufu.br/bitstream/123456789/11798/i/aLuciana.pdf>. Acesso em: 08 nov. 2017.

MACHADO, José Pedro. Dicionário onomástico etimológico da língua portuguesa. Lisboa: Livros Horizonte, 2003. v. I, III.

MOUZART, Benedito. Paca, tatu, cutia: glossário ilustrado de tupi. São Paulo: Melhoramentos, 2015.

PAULA, Maria Helena de. Achegas para o estudo do léxico caipira em Goiás. In: PAULA, Maria Helena de. (Org.). Língua e Cultura: estudos de léxico em perspectiva. Goiânia: Ed. UFG, 2015. p. 133-144.

PEREIRA, Edson Lemos. Pelos caminhos das águas: um estudo da hidromínia da mesorregião Norte maranhense. 2017. 109 f. Dissertação (Mestrado em Letras) Universidade Federal do Maranhão, São Luís, 2017. Disponível em:

<http://tede2:8080/tede/handle/tede/1617>. Acesso em: 09 nov. 2017.

RAMOS, Hugo de Carvalho. Tropas e boiadas. Goiânia. Ed. UFG: Fundação Cultural Pedro Ludovico Teixeira, 1998.

SAMPAIO, Theodoro. O tupi na geografia nacional. Bahia: Secção Graphica da Escola de Aprendizes Artificies, 1928.

SAUSSURE, Ferdinand de. Curso de linguística geral. Organizado por Charles Bally e Albert Sechehaye. Tradução de Antônio Chelini, José Paulo Paes e IzidoroBlikstein. 25 ed. São Paulo: Cultrix, 1996.

SEABRA, Maria Cândida Trindade Costa de. Referência e onomástica. In: Múltiplas perspectivas em linguística: Anais do XI Simpósio Nacional e I Simpósio Internacional de Letras e Linguística (XI SILEL). Uberlândia: ILEEL, 2006. p. 1953-1960. Disponível em: <www.filologia.org.br/ileel/artigos/artigo_442.pdf>. Acesso em: 18 ago. 2017. SIQUEIRA, Kênia Mara de Freitas. Nos trilhos da estrada de ferro: Reminiscências de motivações toponímicas. Revista da ANPOLL, São Paulo-SP, v. 1, n. 32, p. 150-170, 2012. 
Disponível em:

<https://revistadaanpoll.emnuvens.com.br/revista/article/view/618/629>. Acesso em: 11 nov. 2017.

O léxico tupi na nomeação dos lugares goianos nos séculos XVII e XVIII. In:

PAULA, Maria Helena de. (Org.). Língua e Cultura: estudos de léxico em perspectiva. Goiânia: Ed. UFG, 2015. p. 85-104.

Toponímia de origem tupi: relação entre os nomes de lugares goianos e o ambiente. In:COUTO, Elza KiokoNakayamaNenoki do. Linguística ecossistêmica: 10 anos de ecolinguística no Brasil. Campinas, SP: Pontes, 2017. p. 173-190.

; DAVID, Nismária Alves. Topônimos de origem indígena: o papel do tupi na nomeação dos lugares goianos. FRONTEIRAS: Journal of Social, Technological and Environmental Science, Anápolis, Goiás, v.3, n. 1, jan.-jul. 2014, p. 119-131.

TIBIRIÇÁ, Luiz Caldas. Dicionário de topônimos brasileiros de origem tupi. São Paulo: Traço, 2009.

'Disponível em: <biblioteca:IBGE.gov.br/índex.php/biblioteca-catalogo?view=detalhe\&id=440164>.

"Disponível em: <geografia.seed.pr.gov.br/modules/galeria/detalhe.php.foto=365evento=5\#.menugaleria>.

iii Disponível em: <www.mpgo.mp.br/portal/conteudo/bacia-hidrografica-do-rio-meia -ponte\#-Wn.NXJTLRZ4>.

iv Disponível em: <Brasil.gov.br/meio-ambiente/2015/02/ana-disponibiliza-mapa-interativos-da-bacia-dorio-paranaiba>.

` Disponível em: <www.ana.gov.br/portal/ANA/sala-de-situação/tocantins/saiba-mais-tocantins>.

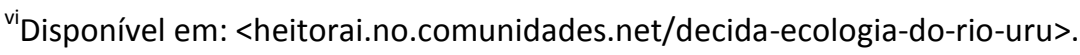

Recebido em 13 de março de 2018.

Aceito em 17 de abril de 2018. 